\title{
Psychological Wellbeing of Saudi Patients Diagnosed with Chronic Illnesses
}

\author{
Ayman M. Hamdan-Mansour ${ }^{1,2}$, Ahmad E. Aboshaiqah³, Imad N. Thultheen ${ }^{4}$, \\ Wisam M. Salim4 \\ ${ }^{1}$ Department of Nursing, Al-Farabi Colleges, Riyadh, KSA \\ ${ }^{2}$ Faculty of Nursing, The University of Jordan, Amman, Jordan \\ ${ }^{3}$ Nursing Administration and Education Department, College of Nursing, King Saud University, Riyadh, KSA \\ ${ }^{4}$ Department of Medical Surgical Nursing, College of Nursing-King, Saud University, Riyadh, KSA \\ Email: a.mansour@ju.edu.jo, aaboshaiqah@ksu.edu.sa, ithultheen@ksu.edu.sa, wsalim@ksu.edu.sa
}

Received 25 December 2014; accepted 5 January 2015; published 16 January 2015

Copyright (C) 2015 by authors and Scientific Research Publishing Inc.

This work is licensed under the Creative Commons Attribution International License (CC BY).

http://creativecommons.org/licenses/by/4.0/

(c) (i) Open Access

\begin{abstract}
Patients' psychosocial status interferes with their ability to manage their physical needs independently affecting health care outcomes. The purpose of this study was to investigate the psychological wellbeing of patients diagnosed with chronic illnesses in Saudi Arabia. A cross sectional survey using 412 patients diagnosed with chronic illnesses has been used to collected data in regards to depressive symptoms, psychological distress and life satisfaction. $17.5 \%$ of the patients reported that they had moderate to severe depressive symptoms, and about $50 \%$ of them had high level of life satisfaction, moderate level of psychological distress. There were significant association between patients' age and depression $(r=.17, p=.003)$, while no significant correlation with life satisfaction and psychological distress $(p>.05)$. Positive and significant correlation found between period of diagnosis and life satisfaction $(r=.16, p=.010)$, and negative and significant correlations with psychological distress $(r=-.13, p=.029)$. Also patients were different in the level of life satisfaction relation to medical diagnoses $\left(F_{5412}=2.74, p=.019\right)$. Patients with chronic illness are in need for psychological care, and periodic psychological screening is one step toward maintaining their psychological wellbeing.
\end{abstract}

\section{Keywords}

Psychological Wellbeing, Depression, Psychological Distress, Life Satisfaction, Chronic Illnesses

\section{Introduction}

Health reform requires assuming more attention towards chronic diseases for their significant role in reforming

How to cite this paper: Hamdan-Mansour, A. M., Aboshaiqah, A. E., Thultheen, I. N., \& Salim, W. M. (2015). Psychological Wellbeing of Saudi Patients Diagnosed with Chronic Illnesses. Psychology, 6, 55-62.

http://dx.doi.org/10.4236/psych.2015.61006 
health research and interventions. Health researchers are became more interested in the comorbidity between chronic physical conditions and psychosocial health consequences such as depression and psychological distress. Previous studies showed that patients with chronic illnesses suffer psychological stressors due to requirement related to management of their physical health problems (Doumit \& Nasser, 2010). However, patients' psychosocial status may interfere in their ability to manage their needs independently which exacerbates their health condition (Sareen, Cox, Clara, \& Asmundson, 2005). It has been found that patients with chronic health conditions suffer number of psychological disturbances such as anxiety and depressive feelings that delays their recovery and healing process (Harter, Conway, \& Merikangas, 2003; Katon, Lin, \& Kroenke, 2007). Therefore, patients with chronic health conditions such as cardiovascular problems, diabetes mellitus, pulmonary disease, and cancer are suffering psychological disturbances while struggling to manage their physical illnesses (Sareen et al., 2005).

The comorbidity of psychological problems with chronic illnesses called for more attention to psychological consequences and its impact on health care outcomes (Al Abeiat, Hamdan-Mansour, Ghannam, Azzeghaiby, \& Dawood, 2014; Khalil, DarAwwad, Al-Gamal, \& Hamdan-Mansour, 2012). Studies showed that psychological difficulties and psychological follow up care were associated with increased morbidity, mortality, expenditure of health services, and burden of caregivers (Dawani, Hamdan-Mansour, \& Ajlouni, 2014; Sullivan, Simon, Spertus, \& Russo, 2002; Wang et al., 2006). In addition, health care professional may sacrifice psychological care and focus only on patients' physiological needs resulting to negatively influencing patients' prognosis and poor treatment outcomes (Frasure-Smith \& Lespérance, 2006; Rozanski, Blumenthal, Davidson, Saab, \& Kubzansky, 2005). According to Chen and Chang (2012), individuals' adjustment to chronic illnesses and their evolved changes of lifestyles have a direct impact on the bio-psycho-social aspects of individual's health. In previous national study (Aboshaiqah, 2014) and similar studies in the Arab region (Al Abeiat et al., 2014; Khalil et al., 2012; Hamdan-Mansour, Farhan, Othman, \& Yacob, 2010; Hamdan-Mansour \& Marmash, 2007) individuals with chronic illnesses have reported number of psychological disturbances such as depression psychological distress and low self efficacy, and those with psychological problems have identified number of physical health problems such as headache low body pains and sleeping problems. Therefore, issues related to social wellbeing, psychological distress, depression and life satisfaction considered important in understanding the process of health-illness continuum, and have not been investigated adequately among the Saudi population.

Managing chronic illnesses is the main concern for policy makers in the Arabian region and particularly in Saudi Arabia. However, the information related to psychological status of patient with chronic illnesses is limited. There is a need to explore the psychological and social wellbeing of those patients especially with the increased cost and demands for health care services globally. Therefore, the purpose of this study was to investigate the psychological health status of patients with chronic illnesses in Saudi Arabia. The specific aims were:

- To describe the psychological wellbeing; depression, psychological distress and life satisfaction of patients diagnosed chronic illnesses in Saudi Arabia.

- To identify the differences psychological wellbeing of patients diagnosed chronic illnesses in Saudi Arabia in relation to selected demographic and personal characteristics; age, gender, working status, medical diagnosis, and period of diagnosis.

\section{Method}

\subsection{Design}

A quantitative approach using cross-sectional, descriptive-correlational design was used to examine correlates of depression among patients with chronic illness. Data was data from patients diagnosed with diabetes mellitus-type-II, Rheumatoid arthritis, CAD (Cardiovascular Disease), cancer, and pulmonary diseases from two major tertiary hospitals in Saudi Arabia. Information collected in regards to depression, psychological distress, and coping using self reported questionnaire.

\subsection{Sample and Settings}

A convenience sampling of 412 completed and retuned the questionnaire. A total of 600 patients approached and invited to study participation and 412 completed and retuned the questionnaire with a response rate of $69 \%$. The study targeted patients attending primary, secondary and tertiary care units. Inclusion criteria include: 1) diag- 
nosed with one of the following chronic illness longer than 6 months: diabetes mellitus-type-II, Rheumatoid arthritis, CAD, cancer, and pulmonary diseases; 2) age of 18 years or above. Exclusion criteria included: no history of diagnosed mental or cognitive disorders.

\subsection{Data Collection Procedure}

Prior data collection, ethical approval obtained from the IRB (Institutional Review Board) at King Saud University, and the targeted institutions. Data collected using self report format of data collection at patient's convenience. Patients who expressed interest to participation in the study were approached by the researcher who explained the study and provided them with all details and answered all their questions. Patients were asked to sign the consent form that included information related to the title of the study, its purpose, its significance and a statement informing the participants that their privacy would be protected by assuring them that their responses will be treated confidentially, and information that reveal their identity will not be recorded. Also, the information will be used for the purpose of the study, and that their participation is voluntary and they have the right to withdraw at any time during the study and that their decision will not influence the quality of care they receive. Anonymity of the respondents ensured during and after study completion; and data secured and saved to provide anonymity. Interviews conducted by trained research assistants at private rooms or patients' rooms upon their convenience. Filling the survey required about 25 minutes and patients who need more time was given opportunity to take break and research assistants retuned to complete filling the questionnaire. The whole package presented in Arabic language.

\subsection{Instruments}

The data collected using an Arabic version of self-reporting questionnaires. The Instruments were:

1) The Beck Depression Inventory-II (BDI-II) (Beck, Steer, \& Brown, 1996) was used to assess patients' depressive symptoms, which contain items that measure cognitive-affective symptoms and attitudes, impaired performance, and somatic symptoms (Beck et al., 1996). This instrument contains 21 questions answered on a four-point Likert scale in which 0 represents the absence of symptoms and 3 represents an extreme problem. The total range of 0 to 63 and standard cutoff points as follow: 0 - 13 indicates no or minimal symptom, 14 - 19 indicates mild symptoms, 20 - 28 indicates moderate symptoms, and 29 - 63 indicates severe symptoms (Beck et al., 1996). A score of 13 is the cut-off point indicating depression. The test-retest $r$ was .88, and Cronbach's Alpha is .87 (Beck et al., 1996). In this study, Cronbach's Alpha was .79.

2) Stress was measured using the brief form of Psychological Stress Measure (Lemyre, Tessier, \& Eillion, 1990). The original Psychological Stress Measure (PSM) was designed using 49 items drawn from descriptors generated by focus groups on stress. The scale is unifactorial in structure and maintains a test-retest stability of .68 to .80 under apparently constant conditions ((Lemyre et al., 1990). Patients checks the answer that best indicates the degree to which each statement has applied to him/her recently The responses made on a Likert scale and ranged from range from 1 (null) to 4 (much). The higher the score in the scale reflect higher level of psychological stress. In this study, Cronbach's Alpha was .81.

3) Life satisfaction was measured using the Satisfaction with Life Scale (Diener, Emmons, Larsen, \& Griffin, 1985). This is a general measure of life satisfaction, which consisted of five statements. Participants were asked to rate each statement according to the following seven-point scale: 1) strongly disagree; 2) disagree; 3) slightly disagree; 4) neither agree nor disagree; 5) slightly agree; 6) agree; and 7) strongly agree. The scores of the total scale ranges from 5 to 35 and interpreted as follow: from 31 - 35 (eextremely satisfied), from 26 - 30 (satisfied), from 21 - 25 (slightly satisfied), 20 (neutral), from 15 - 19 (slightly dissatisfied), from 10 - 14 (dissatisfied), and 5 - 9 (extremely dissatisfied). The test-retest reliability was estimated to be .87 (Diener et al., 1985). In this study, Cronbach's Alpha was .76.

Potential covariates: Gender, age, marital status, type of disease, duration of disease, smoking status, income, Education level and work status. The demographic information obtained from an investigator-developed subject profile.

\subsection{Data Analysis Plan}

The Statistical Package for Social Science (SPSS 20) software (IBM, Chicago, IL, USA) was considered as suitable software for data entry, storage and analysis. Descriptive statistical analysis such as frequency count, 
percentage, mean, median and standard deviation was employed to describe the research sample. The Pearson product moment correlation coefficient was used to describe the association between variables. T-test for two independent samples (or ANOVA as appropriate) was used to compare means and differences. Statistical significance was set at $p>.05$.

\section{Results}

\subsection{Descriptive Characteristics}

A total number of 412 patients completed the questionnaire (see Table 1). Patients' age ranged from 18 to 98 years, with mean of 44.2 (SD = 16.8). About 33.3\% $(n=138)$ of the patients there were male patients, while $66.6 \%(n=272)$ were females. In regard to marital status, the majority of them $28.7 \%(n=243)$ were married, while $5.3 \%(n=25)$ were divorced, and $20.8 \%(n=85)$ were single, and $12.8 \%(n=53)$ were widow. The analysis also showed that most of patients $(58.5 \%, n=242)$ were not working, and $21.0 \%(n=87)$ of them had a full time work, $13.0 \%(n=54)$ had retired, where the least percent $4.5 \%(n=19)$ of patients had a part time work.

In regard to their medical diagnosis, the analysis showed that $32.5 \%(n=134)$ of the patients had diabetes mellitus type-II, $17.5 \%(\mathrm{n}=72)$ had cardiovascular disease, $15.5 \%(\mathrm{n}=64)$ had pulmonary diseases, $19.8 \%(\mathrm{n}=$ $81)$ had rheumatoid arthritis, and $14.7 \%(n=60)$ had cancer.

\subsection{Psychosocial Health Factors}

Depression: Regarding depressive symptoms, the analysis (see Table 2) showed that the patients had a mean score of 14.7 (SD = 10.8) with scores ranging from 0 to 55 . About $50 \%$ of the patients had a score of 13 or above. In regards to level of depression, the analysis showed that $41.1 \%(n=170)$ of the patients found to have no or minimal depressive symptoms, while $13.8 \%(n=57)$ had mild depressive symptoms, $6.8 \%(n=28)$ had moderate depressive symptoms, and $18.4 \%(n=83)$ had severe depressive symptoms. The analysis indicates that about $45 \%$ of the patients are suffering from moderate to severe depressive symptoms compared to $55 \%$ with no to mild depressive symptom.

Life satisfaction: Regarding patients' satisfaction about their life (see Table 2), the analysis showed that patients had a mean score of 24.5 (SD $=6.3$ ) with scores ranging from 7 to 35 . Considering that the possible range of score is 5 - 35, and that the analysis showed that $50 \%(n=206)$ of the patients had a score of 25 or above and $50 \%$ of them had a score between 20 and 29, the results indicate that patients, in general, had high level of satisfaction about their life.

Psychological distress: Regarding patients' psychological distress level (see Table 2), the analysis showed that patients had a mean score of $38.9(\mathrm{SD}=11.9)$ with scores ranging from 12 to 70 . Considering that the possible range of score is $9-72$, and that the analysis showed that that $50 \%(n=206)$ of the patients had a score of 40 or above and $50 \%$ of them had a score between 31 and 47 , the results indicate that patients, in general, had moderate level of psychological distress.

\subsection{Differences in Psychological Factors Related to Demographic Characteristics}

Regarding the relationship between selected demographic characteristic and psychosocial factors, the analysis showed that there was a significant and positive correlation between patients' age and depression $(r=.17, p$ $=.003$ ). while, there was no significant correlation between patient's age and psychological distress or life satisfaction ( $r=.03, p=.609 ; r=.02, p=.692$, respectively). The results indicate that that older patients are more likely to have higher level of depressive symptoms while there is no difference in psychological distress and life satisfaction min relation to age. Regarding relationship between period of diagnosed with chronic illness and psychological factors, analysis showed that there is a positive and significant correlation between period of diagnosis and life satisfaction ( $r=.16, p=.010)$, and negative and significant correlations with psychological distress $(r=-.13, p=.029)$. However, no significant correlation found between period of diagnosis and depression symptom $(r=.004, p=.946)$. The analysis infers that patients with longer period of diagnosis with chronic illness are more likely to have lower level of psychological distress and higher level of life satisfaction.

Regarding gender differences, the analysis showed that there was significant difference between male and female patients in their psychological distress $(\mathrm{t}=-4.0, p>.001)$ with female patients having higher mean score of psychological distress $(\mathrm{M}=36.0, \mathrm{SD}=10.6)$ than male patients $(\mathrm{M}=35.2, \mathrm{SD}=11.5)$. While there were no 
Table 1. Descriptive characteristics of patients diagnosed with chronic illnesses $(\mathrm{N}=412)$.

\begin{tabular}{|c|c|c|}
\hline \multicolumn{2}{|c|}{ Variable } & \multirow{2}{*}{$\begin{array}{c}\mathrm{n} \\
138\end{array}$} \\
\hline \multirow{2}{*}{ Gender } & Male & \\
\hline & Female & 272 \\
\hline \multirow[t]{5}{*}{ Marital status } & Single & 85 \\
\hline & Married & 243 \\
\hline & Widow & 53 \\
\hline & Divorced & 25 \\
\hline & Not working & 242 \\
\hline \multirow[t]{5}{*}{ Working status } & Part-time job & 19 \\
\hline & Full time job & 87 \\
\hline & Retired & 54 \\
\hline & $>$ High school & 169 \\
\hline & High school & 104 \\
\hline \multirow[t]{5}{*}{ Level of education } & Diploma & 32 \\
\hline & Bachelor & 80 \\
\hline & Graduate & 11 \\
\hline & Diabetes mellitus & 134 \\
\hline & Cardiovascular & 72 \\
\hline \multirow[t]{3}{*}{ Medical diagnoses } & Pulmonary & 64 \\
\hline & Cancer & 60 \\
\hline & Rheumatoid arthritis & 81 \\
\hline
\end{tabular}

Table 2. Psychological factors of patients diagnosed with chronic illness $(\mathrm{N}=412)$.

\begin{tabular}{ccccccccc}
\hline Variable & $\mathbf{N}$ & $\mathbf{M}$ & SD & Min & Max & $\mathbf{P}_{25}$ & $\mathbf{P}_{50}$ & $\mathbf{P}_{75}$ \\
\hline Depressive symptoms & 412 & 14.7 & 10.8 & 0.0 & 55 & 6.0 & 13.0 & 23.0 \\
Life satisfaction & 412 & 24.5 & 6.3 & 7.0 & 35 & 20.0 & 26.0 & 29.0 \\
Psychological distress & 412 & 39.0 & 11.6 & 12.0 & 70.0 & 31.0 & 40.0 & 47.0 \\
\hline
\end{tabular}

$\mathrm{P}_{25}$ : percentile $25^{\text {th }} . \mathrm{P}_{50}$ : percentile $50^{\text {th }}$ (Median). $\mathrm{P}_{75}$ : percentile $75^{\text {th }}$.

significant differences found in relation to depressive symptoms $(\mathrm{t}=-.63, p=.530)$ and life satisfaction $(\mathrm{t}=$ $-.40, p=.682$ ) although female patients had higher level of depressive symptoms and life satisfaction.

To examine the differences in psychological factors in relation to working status, one-way ANOVA was conducted. The analysis showed that there was no significant difference in depressive symptoms, psychological distress and life satisfaction related to working status $(p>.05)$. regarding differences in psychological factors related to medical diagnosis using one-way ANOVA (see Table 3), the analysis showed that there were significant differences related to medical diagnoses in patients' life satisfaction $\left(\mathrm{F}_{5412}=2.74, p=.019\right)$. Using post hoc comparison (Scheffe), the analysis showed that patients diagnosed with diabetes mellitus Type-II are significantly different (had lower mean score) $(M=23.3, S D=6.4$ ) from those diagnosed with more than chronic illness (comorbid) and cancer. The results indicate that patients diagnosed with diabetes mellitus Type-II cancer had less level of life satisfaction than those diagnosed with cancer or those who have more than one medical problem (comorbid). On the other hand, there were no significant differences in depressive symptoms and psychological distress in relation to medical diagnoses $(p>.055)$.

\section{Discussion}

Exploring and assessing factors related to psychological wellbeing among patients diagnosed with chronic illnesses became a primary concerns and requirement for health professional caring for this group of people 
Table 3. Difference in psychological factors of patients diagnosed with chronic illnesses related to their type of illness $(\mathrm{N}=$ 412).

\begin{tabular}{|c|c|c|c|c|c|c|}
\hline \multicolumn{2}{|c|}{ Variable } & \multirow{2}{*}{$\begin{array}{l}\mathbf{n} \\
66\end{array}$} & \multirow{2}{*}{$\begin{array}{c}\text { M } \\
34.2\end{array}$} & \multirow{2}{*}{$\begin{array}{c}\text { SD } \\
10.9\end{array}$} & \multirow[t]{2}{*}{$\mathbf{F}$} & \multirow[t]{2}{*}{$p$} \\
\hline \multirow{6}{*}{ Depressive symptom } & Pulmonary & & & & & \\
\hline & CVD & 56 & 37.5 & 10.7 & \multirow{5}{*}{2.02} & \multirow{5}{*}{.074} \\
\hline & Cancer & 90 & 34.0 & 10.7 & & \\
\hline & Rheumatoid arthritis & 84 & 37.9 & 10.5 & & \\
\hline & DM-II & 39 & 33.3 & 12.7 & & \\
\hline & Comorbid & 56 & 34.6 & 10.2 & & \\
\hline \multirow{6}{*}{ Psychological distress } & Pulmonary & 5 & 45.2 & 5.5 & \multirow{6}{*}{1.50} & \multirow{6}{*}{.190} \\
\hline & CVD & 60 & 41.5 & 12.0 & & \\
\hline & Cancer & 99 & 37.9 & 11.6 & & \\
\hline & Rheumatoid arthritis & 99 & 39.8 & 10.3 & & \\
\hline & DM-II & 48 & 36.9 & 11.8 & & \\
\hline & Comorbid & 63 & 38.0 & 13.0 & & \\
\hline \multirow{6}{*}{ Life satisfaction } & Pulmonary & 6 & 20.3 & 10.4 & \multirow{6}{*}{2.75} & \multirow{6}{*}{.019} \\
\hline & CVD & 64 & 25.2 & 6.4 & & \\
\hline & Cancer & 101 & 24.7 & 5.0 & & \\
\hline & Rheumatoid arthritis & 105 & 23.3 & 6.4 & & \\
\hline & DM-II & 50 & 24.0 & 7.3 & & \\
\hline & Comorbid & 69 & 26.3 & 6.1 & & \\
\hline
\end{tabular}

(Honyashiki et al., 2011). Moreover, previous studies emphasized the negative impact of psychological wellbeing on physical health condition of patients with chronic diseases (Hamdan-Mansour, 2010; Hamdan-Mansour, Halabi, \& Dawani, 2009). This study aimed at examining the psychological wellbeing of patients diagnosed with chronic illnesses in Saudi Arabia. The study found, in general, that patients diagnosed with chronic illnesses in Jordan suffer psychological disturbances. A significant number of patients (17.5\%) reported having moderate to severe depressive symptoms, and about $50 \%$ of them had high level of life satisfaction, and moderate level of psychological distress. Demographic variables of patients had varied effect on psychological wellbeing of patients. While age had positive association with depression, period of diagnosis with depression was associated with positively with life satisfaction and psychological distress. Moreover, the study found that gender contributed to psychological distress and depression found to be significantly different in terms of medical diagnosis of patients and medical diagnosis.

International studies aimed at detecting prevalence of psychological disturbances among patients with chronic illness were controversial. While depression reported to be common among patients with chronic illnesses (Anderson, Freedland, Clouse, \& Lustman, 2001; Freedland et al., 2003) similar to findings in this study, others (e.g., Niti, Ng, Kua, Ho, \& Tan, 2007) found that depressive symptoms was less prevalent among patients with chronic illnesses than those with acute illnesses. The literature has also showed that chronic illnesses increased the vulnerability to psychological stressors and psychosocial co-morbidity (Doumit \& Nasser, 2010; Honyashiki et al., 2011) which agrees with the results of this study. Although our study supports those who found that depressive symptoms are prevalent among patients with chronic illnesses, however; we have found that patients had moderate to high level of life satisfaction and moderate level of depression. One possible explanation is that patients had depressive feeling, however; they have also utilized available sources of their life that might enabled them to counterbalance the effect of psychological distress. The results support Lewinsohn's model that patients with chronic illnesses are at risk for depression if their illness affected their ability to function (Lewinsohn et al., 1985). In this study, patients possibly utilized resources available to them to maintain their function that resulted in maintaining their life satisfaction. The study also emphasized the role of length time of being diagnosed with chronic disease as those with longer period were more satisfied about their lives. In conclusion, Saudi patients with chronic illness are suffering psychological disturbances, however; they were able to maintain 
their psychosocial wellbeing that positively reflected on their satisfaction about their life.

This study also found that female patients had higher scores in depression, psychological distress and life satisfaction. The results agree with previous studies (e.g., Freedland et al., 2003, Hamdan Mansour et al., 2014) that female patients had higher scores in depression than male patients, and add to the body of knowledge that gender is significant factors to emphasize while investigating psychological wellbeing among patients diagnosed with chronic disease. Moreover, this study compared three psychosocial factors among five types of chronic illnesses and found that there were significant differences among the five types of chronic illnesses in their life satisfaction, while they were not different in their level of depression and psychological distress. The study disagree with previous study conducted in Jordan (Al-Abeiat et al., 2014), a neighbor country with similar culture and health care system, who has found differences between patients with chronic disease in their level of depression and psychological distress. One explanation is that patients in Saudi Arabia receive counseling services at primary and tertiary care levels that might partially contribute to manage distress and depression. However, the study still addressing the prevalence of psychological disturbances among Saudi people with chronic diseases.

One limitation for this study is that data were cross sectional. A longitudinal study may allow better understanding for a cumulative experience over long period of time.

\section{Conclusion}

Health care professionals are challenged to meet patients' needs with the increased health care demands and high cost of treatment. Psychological needs are amongst that required immediate attention. This study found that although patients had moderate levels of depression and psychological distress, patients were satisfied about their lives. Sociodemographic factors, period of diagnosis, and type of illness had varied impact on psychological wellbeing among patients. The study has an implication for health professionals at the community and primary care settings. There is a need to consider a longitudinal approach to examine differences according to illness stage that will allow addressing the stages of illness and its psychosocial impact. Also, there is a need to assess and screen for psychosocial factors; psychological distress, depression, life satisfaction among patients with chronic illnesses in their routine checkups and visits to outpatients units and those hospitalized. There also a need to assess effectiveness of counseling services and available community resources provided at Saudi health care settings.

\section{References}

Al Abeiat, D., Hamdan-Mansour, A., Ghannam, B., Azzeghaiby, S. N., \& Dawood, L. (2014). Psychosocial Health Status of Patients Diagnosed with Chronic Illnesses in Jordan. Open Journal of Medical Psychology, 3, 281-291. http://dx.doi.org/10.4236/ojmp.2014.34029

Anderson, R. J., Freedland, K. E., Clouse, R. E., \& Lustman, P. J. (2001). Prevalence of Comorbid Depression in Adults with Diabetes. Diabetes Care, 24, 1069-1078. http://dx.doi.org/10.2337/diacare.24.6.1069

Beck, G., Steer, R., \& Brown, G. (1996). Manual for the Beck Depression Inventory-II. San Antonio, TX: Psychological Corporation.

Chen, P. Y., \& Chang, H. C. (2012). The coping process of patients with cancer. European Journal of Oncology Nursing, 16, 10-16. http://dx.doi.org/10.1016/j.ejon.2011.01.002

Dawani, H., Hamdan-Mansour, A., \& Ajlouni, M. (2014). Users’ Perception of Home Health Care Services in Jordan. Health, 6, 549-558. http://dx.doi.org/10.4236/health.2014.67074

Diener, E, Emmons, R. A., Larsen, R. J., \& Griffin, S. (1985). The Satisfaction with Life Scale. Journal of Personality Assessment, 49, 71-75. http://dx.doi.org/10.1207/s15327752jpa4901_13

Doumit, J. \& Nasser, R. (2010). Quality of Life and Wellbeing of the Elderly in Lebanese Nursing Homes. International Journal of Health Care, 23, 72-93. http://dx.doi.org/10.1108/09526861011010695

Frasure-Smith, N., \& Lespérance, F. (2006). Recent Evidence Linking Coronary Heart Disease and Depression. The Canadian Journal of Psychiatry, 51, 730-715.

Freedland, K. E., Rich, M. W., Skala, J. A., Carney, R. M., Dávila-román, V. G., \& Jaffe, A. S. (2003). Prevalence of Depression in Hospitalized Patients with Congestive Heart Failure. Psychosomatic Medicine, 65, 119-128. http://dx.doi.org/10.1097/01.PSY.0000038938.67401.85

Hamdan-Mansour, A. (2010). Predictors of Hostility among University Students in Jordan. Scandinavian Journal of Caring Sciences, 24, 125-130. http://dx.doi.org/10.1111/j.1471-6712.2009.00695.x 
Hamdan-Mansour, A., Halabi, J., \& Dawani, H. (2009). Depression, Hostility, and Substance Use among University Students in Jordan. Mental Health and Substance Use: Dual Diagnosis, 2, 53-64.

Hamdan-Mansour, A., \& Marmash, R. (2007). Psychological Well Being and General Health among Jordanian University Students. Journal of Psychosocial Nursing and Mental Health Services, 45, 31-39.

Harter, M. C., Conway, K. P., \& Merikangas, K. R. (2003). Associations between Anxiety Disorders and Physical Illness. European Archive of Psychiatry Clinical Neurosciences, 253, 313-320. http://dx.doi.org/10.1007/s00406-003-0449-y

Honyashiki, M., Ferri, C. P., Acosta, D., Guerra, M., Huang, Y. et al. (2011). Chronic Diseases among Older People and Co-Resident Psychological Morbidity: A 10/66 Dementia Research Group Population-Based Survey. International Psychogeriatric Association, 23, 1489-1501. http://dx.doi.org/10.1017/S1041610211000500

Katon, W., Lin, E. H., \& Kroenke, K. (2007). The Association of Depression and Anxiety with Medical Symptom Burden in Patients with Chronic Medical Illness. General Hospital Psychiatry, 29, 147-155. http://dx.doi.org/10.1016/j.genhosppsych.2006.11.005

Khalil, A., DarAwwad, M., Al-Gamal, E., \& Hamdan-Mansour, A. (2012). Predictors of Dietary and Fluid Non-Adherence in Jordanian Patients with End-Stage Renal Disease Receiving Hemodialysis: A Cross-Sectional Study. Journal of Clinical Nursing, 22, 127-136. http://dx.doi.org/10.1111/j.1365-2702.2012.04117.x

Lemyre, L., Tessier, R., \& Eillion, L. (1990). Mesure du stress psychotogique (MSP): Manuel d'utilisation [Psychological Stress Measure]. Brossard: Editions.

Lewinsohn, P. M., Hoberman, H., Teri, L., \& Hautzinger, M. (1985). An Integrative Theory of Depression. In S. Reiss, \& R.R. Bootzin (Eds), Theoretical Issues in Behavior Therapy (pp. 331-359). San Diego, CA: Academic Press.

Niti, M., Ng, T., Kua, E. H., Ho, R. C. M., \& Tan, C. H. (2007). Depression and Chronic Medical Illnesses in Asian Older Adults: The Role of Subjective Health and Functional Status. International Journal of Geriatric Psychiatry, 22, 10871094. http://dx.doi.org/10.1002/gps.1789

Rozanski, A., Blumenthal. J. A., Davidson, K. W., Saab, P. G., \& Kubzansky, L. (2005). The Epidemiology, Pathophysiology, and Management of Psychosocial Risk Factors in Cardiac Practice: The Emerging Field of Behavioral Cardiology. Journal of the American College of Cardiology, 45, 637-651. http://dx.doi.org/10.1016/j.jacc.2004.12.005

Sareen, J., Cox, B. J., Clara, I., \& Asmundson, G. (2005). The Relationship between Anxiety Disorders and Physical Disorders in the U.S. National Comorbidity Survey. Depression \& Anxiety, 21, 193-202. http://dx.doi.org/10.1002/da.20072

Sullivan, M., Simon, G., Spertus, J., \& Russo, J. (2002). Depression-Related Costs in Heart Failure Care. Archive of Internal Medicine, 162, 1860-1866. http://dx.doi.org/10.1001/archinte.162.16.1860

Wang, P. S., Demler, O., Olfson, M., Pincus, H. A., Wells, K. B., \& Kessler, R. C. (2006). Changing Profiles of Service Sectors Used for Mental Health Care in the United States. The American Journal of Psychiatry, 163, 1187-1198. http://dx.doi.org/10.1176/ajp.2006.163.7.1187 
Scientific Research Publishing (SCIRP) is one of the largest Open Access journal publishers. It is currently publishing more than 200 open access, online, peer-reviewed journals covering a wide range of academic disciplines. SCIRP serves the worldwide academic communities and contributes to the progress and application of science with its publication.

Other selected journals from SCIRP are listed as below. Submit your manuscript to us via either submit@scirp.org or Online Submission Portal.
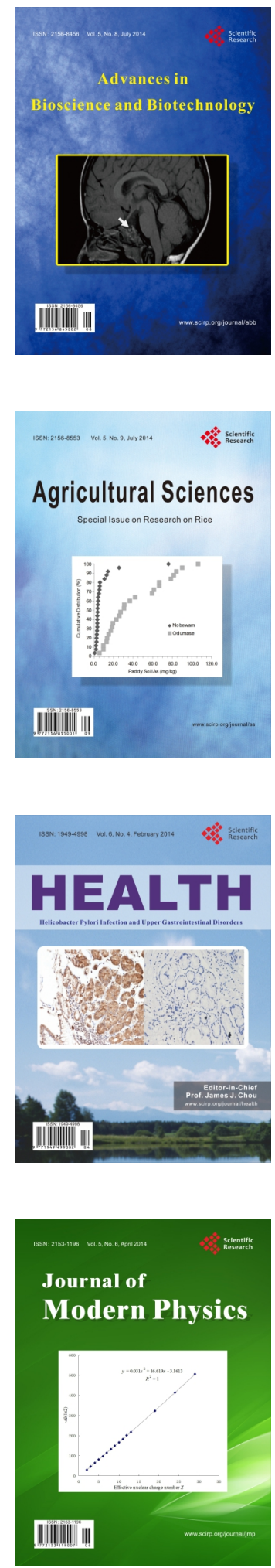
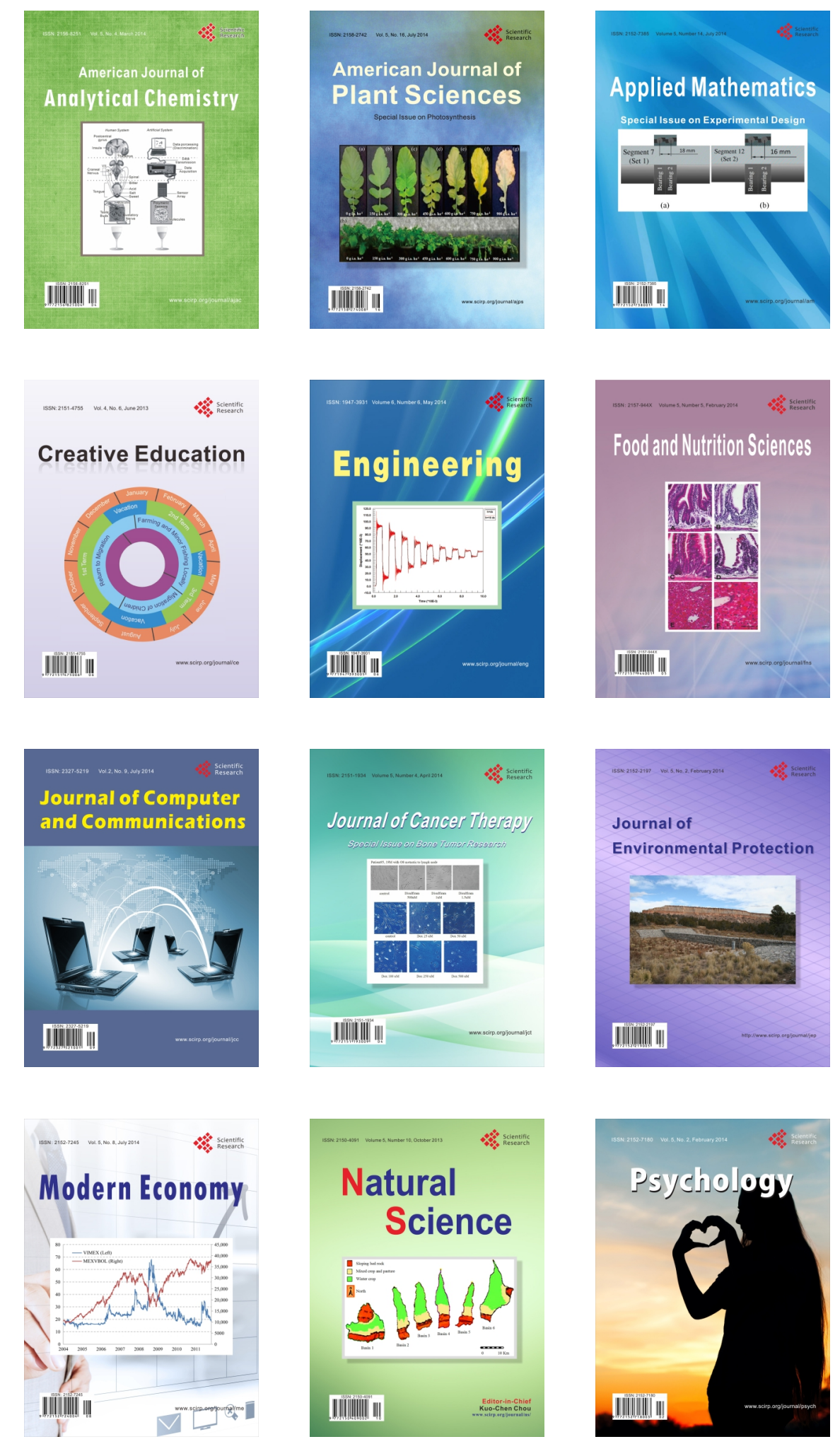